\title{
CONGENITAL MYASTHENIA GRAVIS
}

\author{
BY \\ R. I. MACKAY \\ From the Hope Hospital, Salford
}

(Received for Publication April 10, 1950)

This report of a case of congenital myasthenia gravis and a study of the patient's family are presented not only because of their intrinsic interest, but also because they may help to elucidate this rare condition and to establish it as a disorder of infancy.

The accounts of myasthenia gravis in the textbooks do not usually include references to the condition in infancy. The maximal incidence is in young adults, but many articles have reviewed the cases known to have occurred in childhood. The condition has, however, only rarely been reported in infants.

Levin (1949) described congenital myasthenia gravis in two siblings, and reviewed previous case reports. From these he deduced certain clinical principles concerning the behaviour of myasthenia gravis in young infants.

The case reports can be analysed in three groups.

The first group may be classified as transitory neonatal myasthenia occurring in infants whose mothers suffer from myasthenia gravis. They all show signs of a myasthenic state: general feebleness, poor sucking and swallowing reflexes, drooping eyelids, a mask-like facies, and sometimes sudden, fatal collapse. When such infants were treated for the first two weeks of life with prostigmine, survival and recovery were usual. If prostigmine was not continued, the infants usually died, some after a sudden collapse. Strickroot, Schaeffer, and Bergo (1942) reported such an infant who developed symptoms on the third day, and in whom $3.75 \mathrm{mg}$. of prostigmine bromide, given orally, produced a dramatic response. Omission of the treatment on the fifth day caused a relapse, and although some recovery followed the administration of a double dose, the baby suddenly collapsed and died. At necropsy there was evidence of cerebral congestion and oedema, atelectasis, suprarenal haemorrhages, and diffuse cloudy swelling of other organs with mild hyperplasia of the thymus including hypertrophy of Hassall's corpuscles. Wilson and Stoner (1944) reported two probable cases born to a woman with myasthenia gravis; the first died soon after birth, while the mother was not receiving treatment; the second survived after some initial difficulties, while the mother was having regular maintenance treatment with prostigmine. Neither infant received prostigmine as treatment. Stone and Rider (1949) reported a similar case in which the infant was treated with neostigmine for 14 days, and who survived as a normal child. LaBranche and Jefferson (1949) described a child who responded to prostigmine therapy which was continued for four months. At this age the child's condition was reported as satisfactory, while treatment continued. F. R. Ford reported to Levin, in a personal communication, a baby born with a myasthenic state, who was treated for one week and survived as a normal infant. The various authors imply that this type of myasthenia is due to the transplacental passage of a curare-like substance which affects the baby at birth, but which is destroyed in some manner, and leaves the child unaffected in later life.

In the second group, three cases of congenital myasthenia gravis have been reported in which the accepted clinical picture of myasthenia gravis was present from birth. The mothers were not affected. Bowman (1948) described a child in whom the condition had been present from birth, and who was well maintained on prostigmine. Two cases were described by Levin in the paper quoted. The first was a boy whose symptoms were present from birth as progressive weakness, bilateral ptosis, and limited ocular movements. He responded well to prostigmine therapy, but treatment was discontinued during an acute respiratory infection, and he died. The second case was the boy's younger sister whose condition was suspected in the antenatal period, because the mother felt that foetal movements were not sufficiently strong. Myasthenia gravis was diagnosed at birth, and treatment started at once. Treatment was continuous, and the response satisfactory. The mother was not affected, and no latent myasthenic state could be demonstrated even after large doses of quinine.

Although no other cases of congenital myasthenia gravis have been reported, Levin states certain principles concerning the condition. He suggests 
that in certain circumstances, diminished foetal movements may be noted, implying a prenatal inception of the disorder. He also states that congenital myasthenia gravis differs from the acquired condition in the symmetry of muscular weakness, and that the disorder is neither progressive nor intermittent.

The third group of cases should be called ' infantile' rather than 'congenital,' though the onset of symptoms is noted so early in life that a congenital disorder may be suspected. These cases are often diagnosed after a respiratory infection, and in more than one report there has been a familial incidence. Bowman's cases (1948) include two cousins, and Rothbart (1937) described a family in which four boys were affected, the youngest developing symptoms at the age of six weeks. In this family the course was intermittent and one boy died. A sister was unaffected.

\section{Case History}

The patient is the first born of twin girls born on February 5, 1942. The mother was 30 years old at the time of the confinement, and it was her first pregnancy. The antenatal period was uncomplicated until the 36th week when there was mild hypertension. At term there was heavy albuminuria, and a diastolic blood pressure of $100 \mathrm{~mm}$. Hg. After treatment, she was successfully delivered of twins by natural forces. There was only one placenta, which was expelled intact with membranes.

The patient presented by the vertex, and weighed $5 \mathrm{lb} .3 \mathrm{oz}$; her twin, a breech delivery, weighed $3 \mathrm{lb} .12 \mathrm{oz}$. At the age of 18 days, the twin had gained $1 \mathrm{lb} .1 \mathrm{oz}$. in weight; the patient who had not regained her birth weight, equalled her sister at $4 \mathrm{lb} .13 \mathrm{oz}$. The patient was discharged from hospital at the age of 20 days weighing $5 \mathrm{lb} .1 \mathrm{oz}$. The twin was discharged at 32 days, weighing $5 \mathrm{lb}$. Both babies were initially fed on breast milk, the twin requiring a complementary feed of milk formula. Artificial feeding was necessary soon after she left the hospital.

The mother, who is a reliable witness, described the patient as 'a silly feeder though hungry,' and ' a weakly baby from birth,' whereas her twin was ' a normal baby.' She was overtaken by her twin in growth and progress at 3 months of age. Because of the feeding difficulties, the mother attended a hospital out-patient department when the patient was 3 months old. She was told to enlarge the hole in the teat of the feeding bottle, and given other instructions in feeding technique which she faithfully carried out. The baby did not improve, and seemed too feeble to suck properly. Her twin often finished both feeds.

The children (Fig. 1) attended the welfare centre when they were 1 year old, the mother complaining that the patient was late in walking, and did not jump and play like her sister. At the age of 3 years, she attended hospital on account of bilateral ptosis, and weakness of the legs, but no diagnosis was made. The ptosis was

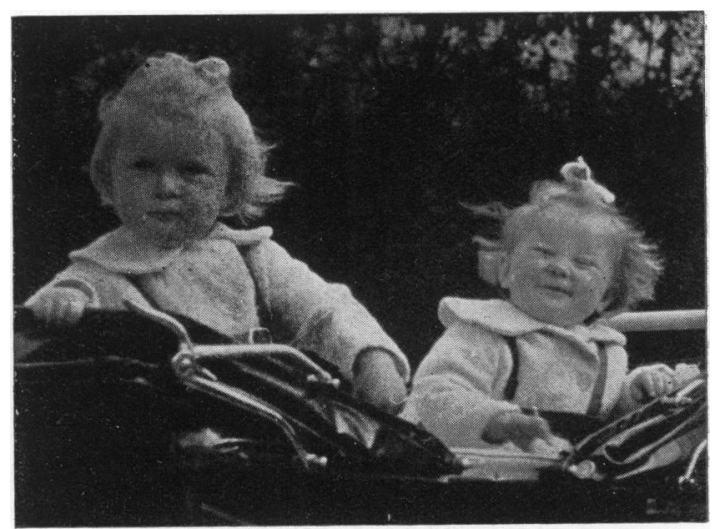

Fig. 1.

later complicated by photophobia. At the age of 4 years she could walk but could not run nor jump (Table 1).

TABLE 1

Comparison of Patient's and Twin's Milestones

\begin{tabular}{ll|l|l}
\hline \multicolumn{1}{c|}{ Activity } & \multicolumn{1}{|c|}{ Patient } & \multicolumn{1}{|c}{ Twin } \\
\hline Sat up.. &.. & at $5-6$ months & 5-6 months \\
\hline Walked &. & at $15-16$ months & 10-12 months \\
\hline Running &. & Only recently & Since infancy \\
\hline Talked &. & at 1 year (first) & 1 year (second) \\
\hline First tooth &.. & 6 months & 9 months \\
\hline
\end{tabular}

A comparison of the performance of the two children shows that the patient eats more slowly, though she may eat more than her twin. There is the greatest difficulty at tea time, though there has never been any nasal regurgitation. The patient finds swallowing and nose blowing difficult. She is easily roused in the morning, but tires more quickly than her sister. She never hurries ; she falls clumsily, and then has difficulty in getting up again. She sweats more than her sister.

The ptosis was first noticed as abnormal in her third year, and it has increased progressively, though less in the early morning; it becomes maximal within half an hour of rising. Movements of the eyes have steadily decreased until they are now almost stationary. She has always been poor at 'face-pulling.' There have been no variations in the degree of weakness, no remissions and no crises of respiratory failure.

In her intellectual activity she is superior to her twin: she is the leader, and speaks more fluently.

No other member of the family is known to be affected

At the first attendance she was 7 years 8 months old anc on examination she was $42 \frac{3}{4}$ in. tall and $37 \mathrm{lb} .1 \mathrm{oz}$. ir weight, while her sister was 45 in. tall and $47 \mathrm{lb} .13 \mathrm{oz}$ 


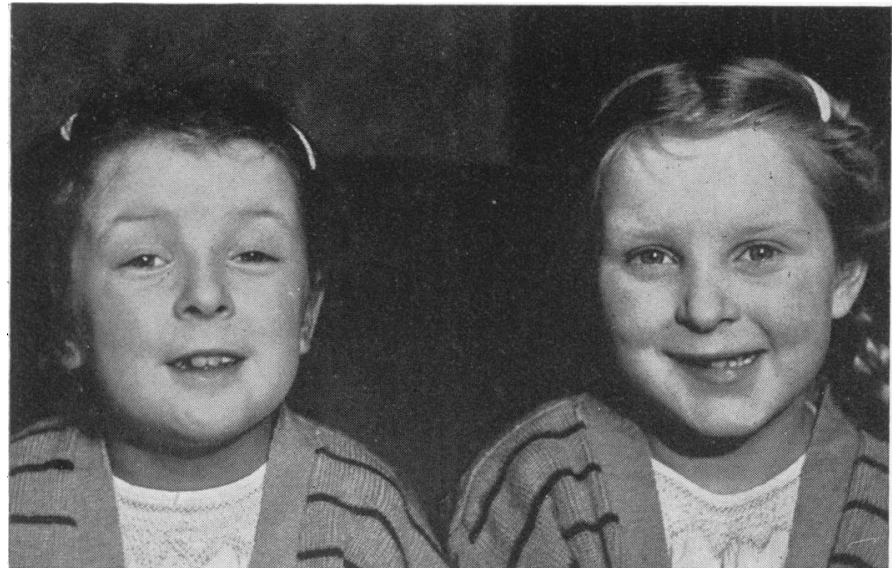

FIG. 2.

in weight. She appeared to be less well nourished than her twin (Fig. 2).

Her face was expressionless, and typically myopathic with bilateral ptosis to the pupil rim, and this caused her to throw her head back in order to see across the room. She had a complete external ophthalmoplegia. Voluntary movements, such as wrinkling the forehead, wrinkling the nose, and opening the eyes widely were virtually impossible. Persistence of grip was poor, that is to say the power to grip was poor in itself, though fatiguability was difficult to judge, because she could not maintain a constant grip. Repetitive movements were not well done, and the impression was gained that her performance was definitely inferior to her sister's. Full clinical examination did not reveal any wasting of skeletal muscles, and no abnormality was found in other systems.

Further laboratory investigation furnished the following information; the norms are taken from Behrendt (1949), quoting Harding and Gaebler.

\begin{tabular}{l|c|c}
\hline & Patient & Twin \\
\cline { 2 - 3 } $\begin{array}{l}\text { Radiograph of chest } \\
\text { Radiograph of skull } \ldots\end{array}$ & $\begin{array}{c}\text { No abnormality } \\
\text { No abnormality }\end{array}$ & - \\
$\begin{array}{l}\text { Wassermann and Kahn re- } \\
\text { actions }\end{array}$ & - \\
$\begin{array}{c}\text { Urinary creatinine coefficient } \\
\text { (Norm for age-less than } \\
18 \cdot 1 \text { ) }\end{array}$ & $\begin{array}{c}\text { Negative } \\
19 \cdot 8\end{array}$ & $16 \cdot 3$ \\
$\begin{array}{c}\text { Urine creatine coefficient .. } \\
\text { (Norm for age-less than } \\
4 \cdot 5)\end{array}$ & $6 \cdot 1$ & $1 \cdot 25$ \\
\hline
\end{tabular}

In view of an earlier suggestion that the twins were uniovular, and because of the implications of such a relationship, it was felt necessary to obtain further evidence on this point.

Fig. 2 indicates that the children are not identical in appearance; nor are they identical in measurements or in their personalities. It is not clear to what extent this is the result of the limitations imposed on the patient by her condition. The patient's hair is darker than her sister's, though both could be classed as blonde. The twin has a clear blue iris, while the patient's iris is a darker blue, and is slightly more pigmented.

Expert opinion was sought on their fingerprints which proved to be dissimilar. The degree to which they differ suggests that the children are binovular twins. The formulae, according to the Edward Henry classification, are as follows:

$$
\begin{gathered}
\text { Patient } \frac{\text { O. A. AII. } 6}{\text { O.aA. AMM. } 12} \\
\text { Twin } \frac{\text { O. U. IMO. } 8}{\text { O. U. MMI. } 2}
\end{gathered}
$$

Detailed study of the blood groups of the whole family was performed, with the following result (Table 2), and

\begin{tabular}{|c|c|c|c|c|}
\hline Group & Father & Mother & Patient & Twin \\
\hline $\mathrm{ABO} \quad \cdots$ & $A_{1}$ & O & $\mathbf{A}_{1}$ & $\mathbf{A}_{1}$ \\
\hline $\mathrm{Rh} \quad \ldots$ & $\mathbf{R}_{\mathbf{2}} \mathbf{R}_{2}$ & $\mathrm{R}_{1} \mathrm{r}$ & $\mathbf{R}_{1} \mathbf{R}_{2}$ & $R_{1} R_{2}$ \\
\hline MNS $\ldots$ & MNS & MNS & MS & MNS \\
\hline $\mathbf{P} \quad \ldots$ & Neg. & Pos. & Pos. & Pos. \\
\hline Lewis $\quad \ldots$ & $a-b+$ & $a-b-$ & $a+b-$ & $a-b+$ \\
\hline Kell .. & Pos. & Neg. & Neg. & Neg. \\
\hline Lutheran & Neg. & Neg. & Neg. & Neg. \\
\hline Duffy $\ldots$ & Neg. & Neg. & Neg. & Neg. \\
\hline Secretor & $\begin{array}{l}\text { Secretor } \\
(\mathrm{A} \& \mathrm{H})\end{array}$ & $\begin{array}{l}\text { Non- } \\
\text { secretor } \\
\text { (H) }\end{array}$ & $\begin{array}{l}\text { Non- } \\
\text { secretor } \\
\text { (A \& H) }\end{array}$ & $\begin{array}{l}\text { Secretor } \\
(\mathrm{A} \& \mathrm{H})\end{array}$ \\
\hline
\end{tabular}
this evidence also suggests that the twins are binovular.

TABLE 2

Blood Group of Patient's Family

An attempt was made to obtain the myasthenic reaction of Jolly, and to assess muscle fatiguability objectively by electrical stimulation, but the child was frightened by the sensations and could not cooperate. The attempt was abandoned.

The therapeutic test was positive. Within 15 minutes of the subcutaneous injection of $1 \mathrm{mg}$. of neostigmine methyl sulphate with $1 / 150 \mathrm{gr}$. atropine sulphate, the ptosis could be overcome completely to show a rim of sclera above the iris (Figs. 3 and 4), facial grimacing was possible, and repetitive actions more sustained, though precise observation was difficult.

Far more obvious and satisfactory were the comments 


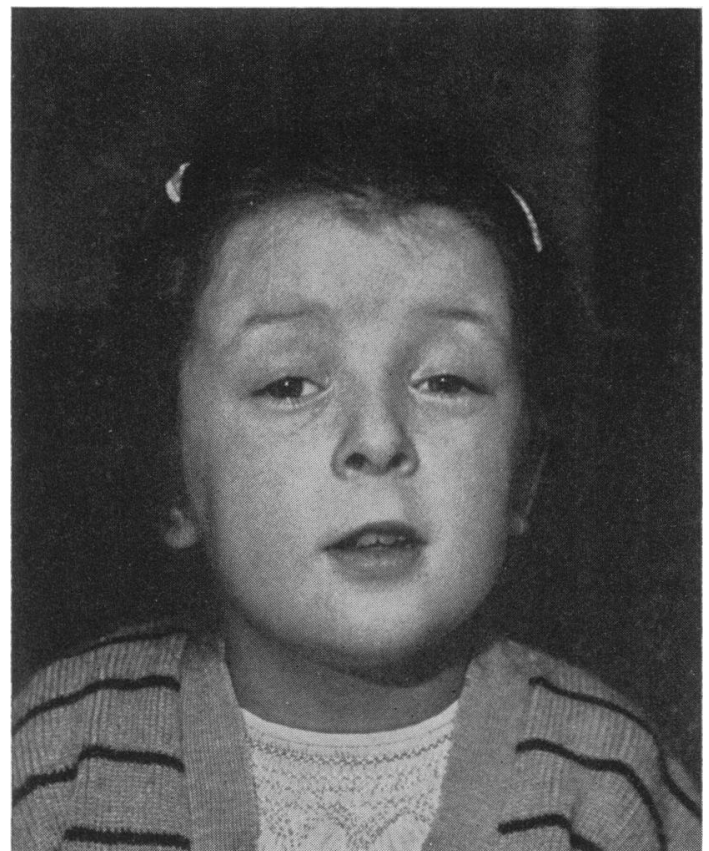

FIG. 3.-Before therapeutic test.

of her mother and friends when she returned home on a maintenance treatment of $10 \mathrm{mg}$. of neostigmine methyl sulphate by mouth three times daily. "Her voice is so loud now,' 'she sings and shouts such a lot,' 'I've never seen her run before, and now she runs everywhere,' were her mother's comments. Her school teachers were amazed at her new vigour and energy. Her Brownie leader reported that she took part in games which had previously been beyond her powers. The patient herself is aware of the effect of the powders, and can now feel when one is required. Her mother regulates the daily dosage according to need. In general, she requires $12 \mathrm{mg}$. three times daily at present, the last dose usually being taken no later than 3 p.m. Apart from her increased activity, she gained $3 \mathrm{lb}$. in weight and $1 \frac{1}{4} \mathrm{in}$. in height in the first six weeks of treatment. Approximately 10 months later her weight was $39 \mathrm{lb}$. $4 \mathrm{oz}$. (total gain $2 \mathrm{lb} .3 \mathrm{oz}$.) and her height $44 \frac{1}{2}$ in., showing a total gain of $1 \frac{3}{4}$ in., while her sister weighed $47 \mathrm{lb} .14 \mathrm{oz}$., a total gain of $1 \mathrm{oz}$., and measured $47 \frac{1}{2}$ in., a total gain of 2 in.

Although there was no obvious variation in her myasthenic state before treatment began, she has 'been poorly in the night ' on two occasions in recent months. The attacks have begun with a light dry cough in the early evening which would not respond to homely measures of treatment. During the night, she has been unable to sleep because the cough was persistent, and she became frightened by a feeling of suffocation. She became more exhausted, and eventually slept in the early hours of the morning. The next day she seemed normally active, though sleepy. On these occasions she has had no prostigmine from 3 p.m. in the afternoon until 8 a.m. the next morning and the attacks followed days of unusual excitement or activity.

Bearing in mind the case reports of congenital myasthenia gravis in which there was a familial incidence, it was decided to test the unaffected members of the patient's immediate family for latent myasthenia, using a modification of the curare test as suggested by Bennet and Cash (1943). It was anticipated that the twin might have a latent myasthenic state demonstrable as undue sensitivity to curare.

In consultation with Dr. M. Boyle, it was decided to inject a test dose of d-tubocurarine chloride amounting to approximately $0.2 \mathrm{mg}$. per stone $(0.03 \mathrm{mg}$. per $\mathrm{kg}$.) of body weight. In fact, both parents received two doses of $1 \mathrm{mg}$. tubocurarine within four minutes, and the twin received two doses of $0.5 \mathrm{mg}$. This represents slightly more than $\mathbf{0 . 2} \mathrm{mg}$. per stone, but was a more convenient dose to administer. Both before and three minutes after the first injection of tubocurarine, muscular function was assessed by observation of ptosis, ocular movement, diplopia, swallowing, speech, and maintenance of power of repeated grips of the examiner's hand. An ergograph could not be obtained for the test. Three minutes after the second injection the tests were repeated.

At no time did either of the parents or the twin show any alteration in muscle power as demonstrated by these tests; in fact, they did not even show the degree of alteration as shown by 'normal' patients regarded as ' hypersensitive ' to test doses of tubocurarine. Therefore no myasthenic state could be demonstrated in these members of the patient's family.

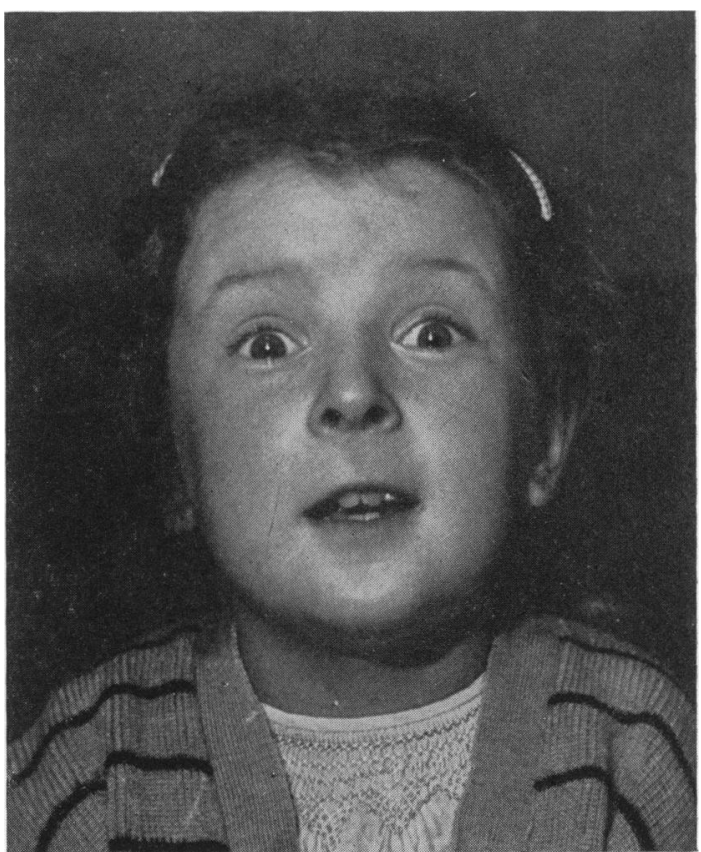

FIG. 4.-Fifteen minutes after therapeutic test. 
This child's history agrees in some respects with the observations of Levin. The muscular weakness is symmetrical, and there has been no obvious variation in the severity of the myasthenia. The disability has, however, been slowly progressive from birth, and the nocturnal attacks since the beginning of treatment may be ' withdrawal' symptoms in the late evening rather than true crises.

Although the results of estimations of urinary creatine and creatinine are not completely satisfactory, they do confirm the diagnosis in the patient and are nearer normal in the twin. This is in keeping with the results of the curare test. There is thus no suggestion of a familial incidence. (Wilson and Stoner also mention an adult patient who had a normal twin.)

When considering the aetiology of this disorder in the light of current theories, some difficulties arise. If myasthenia gravis is a constitutional disorder, in what ways do the constitutions of these twins differ?

Wilson and Stoner, discussing the theories of causation, discount the view that cholinesterase metabolism is abnormal on the basis of serum cholinesterase studies. They also show that myasthenic patients produce normal quantities of acetylcholine (it has been noted that the patient sweats more than her twin, but this has not been proved objectively), and do not favour this theory. Their opinion is that myasthenia gravis is due to the action of some 'curare-like' substance blocking the myoneural receptor mechanism. This view is supported by the clinical picture of the condition 'transitory neonatal myasthenia.' A 'curare-like' substance did not produce any observable effect in the normal twin, though it was considered too dangerous to complete the experiment by administering tubocurarine to the patient. Does this imply that some third factor is necessary before symptoms appear in the myasthenic patient? Such a factor would not be excluded by the experiments conducted by Wilson and Stoner, unless it can be excluded in the laboratory frog-muscle preparations used.

\section{Summary}

A case of congenital myasthenia gravis in one of binovular twins is described.

No latent myasthenic state could be demonstrated in the twin or the parents by injection of d-tubocurarine.

Arising out of this study, certain speculations are made on the aetiology of myasthenia gravis.

I am indebted to a number of persons whose expert knowledge has contributed evidence for this paper. I wish to thank Dr. M. Boyle, consultant anaesthetist to the Salford Hospital Group, who devised and cooperated in the tubocurarine tests; Dr. F. Stratton and Dr. P. Renton, of the National Blood Transfusion Service, for performing the tests of blood groups; Detective Sergeant J. Simpson of the Salford City Police, who examined finger prints; Mr. G. Ward, clinical photographer to the Duchess of York Hospital for Babies, Manchester, for the photographs, and the laboratory and nursing staff of Hope Hospital for their assistance.

My thanks are also due to Professor Wilfred Gaisford for his advice on the preparation of this report, and to the twins and their parents for willing cooperation at all times.

\section{REFERENCES}

Behrendt, H. (1949). 'Diagnostic Tests for Infants and Children,' p. 174. New York.

Bennett, A. E., and Cash, P. T. (1943). Arch. Neurol. Psychiat., Chicago, 49, 537.

Bowman, J. R. (1948). Pediatrics, Springfield, 1, 472. LaBranche, H. G., and Jefferson, R. N. (1949). Ibid., $4,16$.

Levin, P. M. (1949). Arch. Neurol. Psychiat., Chicago, $62,745$.

Rothbart, H. B. (1937). J. Amer. med. Ass., 108, 715.

Stone, C. T., and Rider, J. A. (1949). Ibid., 141, 107.

Strickroot, F. L., Schaeffer, R. L., and Bergo, H. L. (1942). Ibid., 120, 1207.

Wilson, A., and Stoner, H. B. (1944). Quart. J. Med., 13, 1 . 